\title{
THE DEVELOPMENT OF THE CHILD'S PERSONALITY AND THE CONTRIBUTION OF THE SOCIAL AND CULTURAL ENVIRONMENT
}

\author{
Paraskevi Foti ${ }^{1 i}$, \\ Maretta Sidiropoulou ${ }^{2}$ \\ ${ }^{1}$ Educational Coordinator, \\ Regional Directorate of Primary and \\ Secondary Education of Attica, \\ Athens, Greece \\ ${ }^{2}$ Adjunct academic staff, \\ Hellenic Open University (HOU), \\ Athens, Greece
}

\begin{abstract}
:
The development of a child's personality, and in general its evolution, is directly related to social relations and is influenced by cultural processes. The child actively participates in its development, shapes its personality and constantly adapts to the new social and cultural elements that characterize the "Environment". Through this review research that has been done, we will explore how the socio-cultural environment influences the personality and evolution of a child in general and issues of diversity and culture will emerge.
\end{abstract}

Keywords: personality, environment, cultural differences, child's development

\section{Introduction}

The first years of a child's life are full of changes in a variety of areas such as: physical development, physical skills, language, communication, social relationships, play and cognitive skills. These changes occur in all children, in all environments and in all societies and are essential elements in the development of a child's personality and development. Especially, play can be seen as an "intellectual construct" as there are important social, emotional, aesthetic, scientific and cultural meanings embedded in play. (Fromberg and Bergen 2015). 
"...We call evolution from walking to walking, from talking to speech, from concrete thinking to abstract thinking. In any case, the later stage is judged to be more satisfactory than the previous one" (Mussen et all, 1984).

Evolution takes place in cognitive functions (Nicky Hayes, 1997) such as perception, attention, thinking, memory, language, in biomedical functions starting from the reflective infant movements of a stimulus (reflective Babinsky) we gradually reach the specialized, autonomous impulse, speed, preparedness and strength (Paraskevopoulos, 1985) but also in socio-emotional development, through daily contacts with family, teachers, through play and social interactions.

These changes follow some predictability which according to Salkind (1990) is the result of the interaction between biological and environmental factors, while according to M. Cole (1992) except biology and the environment, the individual and society, these two factors do not act directly but are filtered by a third factor, culture. to M. Cole (1992) except biology and the environment, the individual and society, these two factors do not act directly but are filtered by a third factor, culture.

Schaffer (1996) argues that these changes are caused by internal factors that are inherent in children and result from their maturation but also by external factors that have their roots in the child's environment and especially in the early part of the environment. of his life. The influence of parents on a child is critical in the first years of life. In the following years, the child is also under the influence of other people such as: brothers, relatives, teachers, peers and in recent years under the influence of the media and especially television.

He argues that the child develops an active and passive role in his development, that is, he is active in defining what is called an 'effective environment' for his development. His behaviour is made meaningful by the relationships within which it is embedded, and those relationships are embedded in systems such as families.

All of the above factors can influence, each in his or her own way, and contribute to the shaping of his or her growing personality and evolution in general. Teaching, practicing, promoting patterns of imitation, praise, punishment are some of the ways in which adults influence children and consciously or unconsciously attempt to modify, direct, or even change children's behaviour in accordance with what they consider themselves desirable. This is also the case with the socialization, that is, the transmission of acceptable social norms, the norms of behaviour adopted by the particular society in which a child is raised and destined to live (Schaffer, 1996).

\section{Environment and Area of Evolution}

Piaget, Gesell and Skinner spoke about the Environment and expressed differing views on how it affects the development of the child. (Cole, M., Cole, S. 1989). Schaffer (1996) argues that it must be made clear that the behaviour of each child is made meaningful by the relationships within which the child is integrated. These relationships are in turn 
embedded in systems such as families and can only be understood within the context of which they are a part.

The child does not remain passive but active in defining the "effective environment" while the adult structures the environment to attract the child. The influence of the environment is limited by the child's activity and receptivity. But how does the socio-cultural environment affect the child's personality and development in general?

Harkness and Super (1977) studying Kipsigis in Kenya, introduce the concept of the evolutionary region which is an environment in which behaviour is manifested and adapted. In order to develop the personality and overall development of a child, not only the physical and social environments such as the family, the school environment in which the children live but also the culturally regulated customs and upbringing practices of the child play an important role. parents who include goals and priorities for nurturing and care and more generally how families and their surroundings are organized.

In his work The World Until Yesterday (2012) Diamond argues in favour of permissive attitudes towards child-rearing common to many tribes. Far from being harsh towards children, many tribes and groups adopt highly permissive attitudes. If a mother or father among African pygmies hits a child, that would be grounds for divorce. There is no physical punishment allowed at all in these societies. But if a child plays with a sharp knife and waves it around, parents don't intervene. Children will cut themselves on some occasions, but society figures it is better for the child to learn the hard way early in life. They are allowed to make their own choices and follow their own interests. (McKie 2013).

In addition, the infants of hunter-gatherers spend the whole day in their mother's arms, even when she is looking for food while sleeping next to her during the night. According to Diamond, this carnal infant-mother contact, which is increasingly declining in Western societies (children are transported in strollers, sleeping in separate rooms and left to play in bed parks), contributes to children being socially adapted to huntergatherers' breeds while socially isolated the children of Western societies. (Diamond 2014: 222-227, 238-253)

Rogoff and her colleagues (1993), through the findings of a large intercultural research in the two development areas, Maya and Salt Lake City, concluded that:

"In communities where children's activities are separated from adult activities, children's learning can be organized through adult teaching and encouragement outside of the adult environment in communities where children are integrated into adult environments. it can occur through active observation and participation of children with the help and response of those who care for them." (Rogoff 1993, p. 151)

Therefore, the roles of the adult and the child vary according to the environments and goals, as well as the parent's role and role. Rogoff (1990) describes a wide variety of ways in which mothers usually interact with their children. In some cultures, for example, 
eye contact with toddlers seems to be completely avoided while in others it is strongly sought after. In some communities' adults are telling and giving instructions to young children while in others infrequent explanations are given to children on how to do something but on the contrary learn by example or by making assumptions.

Tobin et al. (1989), referring to a pre-school class in Japan and studying the behaviour of the young Hiroki in Komatsudani, pointing out the completely different perception that Chinese observers have of American behaviour while Nsamenang and Lamb (1994), describing Nso. in Cameroon have argued that children's emotional and cognitive development is dependent on and shaped by the socio-cultural environment, and they have typically emphasized that socio-emotional and cognitive skills are closely linked. women with familiar tasks and interpersonal relationships involving children and adults.

Parents' intuitive behaviour is regulated by sociocultural environments while, as Schaffer (1996) points out, speech, reading, play are powerful cultural tools through which children learn how to communicate to think and expand their relationships. The adults who create the right environment and provide the necessary care for the child using appropriate techniques and tools designed to promote human evolution while educators in the formal environment help to shape the personality of the young child. (Sidiropoulou and Schiza 2014)

Urie's ecosystem theory ("ecosystem theory") Bronfenbrenner, (1997) highlights the multiplicity of the concept in its main points "Environment" and the complexity of the relationship between the individual and in the environment and has been recognized as one of the major new insights into developmental psychology (see, for example, Aldridgeetal., (Aldyidge, 1997) (Thomas, 1996).

According in his theory, human development consists of a process of adaptation to the individual characteristics of its ecological context and is effective a synergy of individual, social, economic, political and cultural parameters. The person, his or her experiences, personality, and self-image constitute a constituent of the whole "system" into which they belong and part of which is the individual.

So, to understand the relationship of the person with the environment, the aim of scientific research should be to examine all of these parameters in order to understand how each parameter or a set of parameters, separately, but also in relation to the other as if they affect the person.

"While, other theories ... emphasize the complex interaction between heredity and the environment in relation to the specific historical period in which the individual lives, Bronfenbrenner (1994) divides the environment into several individual contexts systems of individuals and relationships. He accepts that historical effects are only part of the effects that a person receives. His theory Bronfenbrenner offers is an ecological model of development, which emphasizes that the individual is an element of a wider, complex system, and a change in one element brings about a change in all elements of the system." (Bronfenbrenner U., 1997, pp. 185-186). 
So these are the processes, the events and the conditions that they control, control and govern lifelong development in real environments, in which man lives and moves, they are at the centre of his theory and research of a modern bioecological model model for human development, presented by Urie Bronfenbrenner.

There is a dynamic balance between the developing individual and his constantly changing environment with the help of continuous and reciprocal feedback from both parties. Any changes that occur are bi-directional in nature, as changes in the environment automatically cause changes in the individual while changes occur in the individual can cause changes in its environment, in a lifelong relationship.

Bronfenbrenner (1979) has attempting to understand the complexity that characterizes the relationships that are formed in the child's environment, proceeded to separate the frameworks - systems that each of them differently affect their development. The ecological levels that it distinguishes are: micro-system, mesosystem, external system, macrosystem and time system.

According to Berry's ecological model, human diversity must be viewed as a collective and individual adaptive process to the environment. Thus, the characteristics of individuals who are not in association with what is considered acceptable by another group must be an evolutionary adaptation to ecological and socio-political impacts. The goal of the Berry model is to arrive at intercultural sociopsychological explanations for the observed ecological and cultural phenomena occurring (Berry, 1998), (Berry, 1999), (Segall, Berry, \& Poortinga, 1993).

In keeping with the ecological model, education has a central role in the ecosystem approach. According to Bronfenbrenner (1986) and (1989) an understanding of human development requires going beyond the immediate observation of the behaviour of one or the other part of the same couple of individuals. It requires consideration of multifaceted trading systems, which is not limited to a single framework, but must also consider aspects of the environment beyond the immediate control situation of the individual.

Therefore, human development is not a one-way process occurring in a vacuum, but a complex and two-way interaction between the individual and the environment. Thus, our lives are characterized by two-way, complex and multi-dimensional trading processes that take place in the spacetime of the family, kindergarten, kindergarten, school of the workplace, and many other environments. The behaviour is interpreted within a network of relationships where one member of the ecosystem interacts with the perceptions and behaviour of other members of the system. Therefore, in the above researches we observe the different 'environments' in which children are raised and the visions formulated, and we understand how important the concept and dimension of the 'environment' is in developing the personality and development of the child from the beginning, from the first days of his birth but also in the formal school environment, which is a landscape of multilevel communication (Sidiropoulou and Tsaoula 2014) 


\section{Adherence and socio-cultural factors}

The child's early relationships are of fundamental importance and emotional value because they shape the nature of social relationships and form the basis of children's growing perception and experiences of learning and teaching. The child develops a longlasting emotional bond with the person who cares for it, which is called attachment, while from infancy it has the ability to form many attachments simultaneously and not only to the mother's face. The child chooses the object of attachment regardless of who cares about his or her physical care or the time he or she devotes to it. Quality, not quantity of social interaction, is the basis for attachment.

But in adherence, Harkness \& Super studying infants born in Kenya's rural community prove to us that these children grow up in a very different environment of attachment compared to infants from America or Europe. Reactions are differentiated through the organization of daily life and we have varied and different reactions to exactly the same situation. The evolution of attachment relationships is largely influenced by socio-cultural processes.

The way in which care is organized and the cultural perceptions that prevail affect children's emotional development. The way in which care is organized and the cultural perceptions that prevail affect children's emotional development. Harkness and Super, (1977), argue that different cultural processes shape global evolutionary processes according to cultural expectations for communication, social relations, and the evolution of the sense of self.

Research has shown that differences in the degree of attachment security are caused by different ways of raising children, as Schaffer typically points out (1996). The same conclusion is reached by Cole (1992) who argues that the way in which attachment is expressed depends on the cultural care of the child on the children's personal history of separation and reunification exercises and on the cultural meanings attributed to separation in individual families and the wider society.

After all, Singer (1993) emphasizes children as social actors who negotiate relationships that make them feel secure and specialize in the environment even though they may have common needs at the same time. Following Cole and Singer's arguments, we accept the idea that separations and reunions have different meanings for children in different cultural and social settings.

The emotional and cognitive dimensions of social relationships extend beyond attachment (Schaffer, 1996). They shape children's perceptions of themselves in relation to others as this internal model is generalized, as well as expectations for all subsequent relationships (Bowlby, 1969). Babies with secure attachment develop sociality, selfesteem, are less likely to have problem behaviours, and less likely to exhibit adaptive difficulties at older ages, while at the same time demonstrating autonomy in play and more confident in themselves. However, as Schaffer (1996) points out, the child can become autonomous and unsafe attachment is not fate. 


\section{Conclusion}

In this review article we have emphasized the development of personality and the development of a child in general in a way that is integrated into social relationships and is influenced by cultural processes. A child actively participates in its development, shapes its personality and constantly adapts to the new social and cultural elements that characterize the "Environment".

Therefore, human development is not a one-way process it occurs in a vacuum, but a complex and two - way interaction between the individual and environment. Thus, our lives are characterized by two-way, complex and multidimensional trading processes occurring over time of the family, kindergarten, his school workplace and many other environments.

\section{References}

Aldyidge, J. S. (1997). Examining contributions of child development theories to early childhood education. College Student Journal, p.p. 31, 453-459.

Berry, J. W. (1998). Acculturative stress. In P. B. Organista \& K. M. Chum (Eds.), Readings in Ethnic Psychology (pp 117-122). London: Taylor and Francis/Routledge.

Berry, J. W. (1999). Intercultural relations in plural societies. Canadian Psychology, 40, 1221.

Bowlby, J. (1969). Attachment. Attachment and loss: Vol. 1. Loss. New York: Basic Books. Bronfenbrenner, U. (1997). "The ecology of developmental processes" in R. M. Lerner, Handbook of child psychology (vol. 1: Theoretical models of human development). New York: Wiley.

Bronfenbrenner, U. (1994). Ecological Models of Human Development. Oxford: Elsevier.

Bronfenbrenner, U. (1989). Annals of Child Development. Ecological systems theory. , p.p. $6,187-249$.

Bronfenbrenner, U. (1986). Ecology of the family as a contex for human development: Research perspectives. Developmental Psychology, p.p. 22, 723-742.

Bronfenbrenner, U. (1979). The ecology of human development: Experiments by nature and design. Cambridge, MA: Harvard University Press .

Cole, M. 1992. "The Role of Culture in Child Evolution", in Woodhead, M./Faulkner, D./Littleton, K. (ed.), Cultural Worlds of Early Childhood, Patras: EAP.

Cole, M., Cole, S. (1989). The development of children. New York : Scientific American Books.

Denzin, N. (1975). Play, Games and Interaction: The Contexts of Childhood Socialization. The Sociological Quarterly, 16(4), 458-478. Retrieved May 20, 2020, from www.jstor.org/stable/4105940.

Diamond J. (2014). The World Until Yesterday: What Can We Learn From Traditional Societies?. transl. V. Papadopoulou, N. Eliades, Athens: Katoptro. 
Fromberg D. and Bergen D. (eds) (2015). Play from Birth to Twelve: Contexts, Perspectives, and Meanings. New York: Routledge. 3rd ed.

Harkness, S., Super, C. (1977). Why African children are so hard test" in L.L. Adler (ed) Issues in Cross - Cultural Research. Annals of the New York Sciences 285 :326 -31.

Hayes Nicky. 1997. Introduction to Cognitive Processes. Athens: Greek Letters.

Mussen, P. H., J. J. Conger and J. Kagan (1984). Child Development and Personality. New York: Harper Collins.

McKie R. (2013). Jared Diamond: what we can learn from tribal life. The Observer Anthropology, The Guardian. Retrieved May 18, 2020 from https://www.theguardian.com/science/2013/jan/06/jared-diamond-tribal-lifeanthropology.

Nsamenang, B., Lamb, M. (1999). "The Socialization of NSO Children in the Bamenda Grassfields of Northwest Cameroon" in Cultural Worlds of Early Childhood EAP: Patras.

Paraskevopoulos I. N. (1998). "Evolutionary Psychology" vol. 1, 2, Infancy, Preschool, Athens: University of Athens.

Rogoff, B., Mistry, J., Goncu, A., Mosier, C. (1993). “Guided participation in cultural activity by toddlers and caregivers" in Monograph of the Society for Research in Child Development, 58(8) no. 236.

Rogoff, B. (1990). Apprenticeship in Thinking: cognitive development in social context. New York: Oxford University Press.

Salkind, N. J. (1990). Theories of Human Development. Athens: Patakis.

Segall, M., Berry, J., \& Poortinga, Y. (1993). Intercultural Psychology. The study of human behavior in a global eco-cultural context (supervised by Greek publisher D. Georgas).

Athens: Greek Letters.

Schaffer, H. R. (1996). Social Development. Oxford: Blackwell.

Sidiropoulou F., Tsaoula N. (2008). Kindergarten and Research. Multilevel communication landscape. Athens: Epsilon Books

Sidiropoulou, T. Schiza M. (2014). “The Relationships with their Educators" in: The Cyprus Journal of Sciences.Vol.12,2014/17-27.

Singer, E. (1999). "Child Care Inside and Out of the Home" in Woodhead, M./Faulkner, D./Littleton, K. Cultural Worlds of Early Childhood. Patras: EAP.

Thomas, R. (1996). Comparing theories of child development. Belm and: MA.: Wadsworth.

Tobin, J., Wu, D., Davidson, D. (1999). "Komatsudan: A Japanese Preschool Center" in Woodhead, M./Faulkner, D./Littleton, K. (ed.), Cultural Worlds of Early Childhood. Patras: EAP. 

to copy, distribute, transmit or adapt the article content, providing a proper, prominent and unambiguous attribution to the authors in a manner that makes clear that the materials are being reused under permission of a Creative Commons License. Views, opinions and conclusions expressed in this research article are views, opinions and conclusions of the author(s). Open Access Publishing Group and European Journal of Education Studies shall not be responsible or answerable for any loss, damage or liability caused in relation to/arising out of conflicts of interest, copyright violations and inappropriate or inaccurate use of any kind content related or integrated into the research work. All the published works are meeting the Open Access Publishing requirements and can be freely accessed, shared, modified, distributed and used in educational, commercial and non-commercial purposes under a Creative Commons Attribution 4.0 International License (CC BY 4.0). 